\title{
New Advances Reconstructing the Y Chromosome Haplotype of Napoléon the First Based on Three of his Living Descendants
}

\author{
Gérard Lucotte $^{1} \&$ Peter Hrechdakian ${ }^{2}$ \\ ${ }^{1}$ Institute of Molecular Anthropology, 44 Monge Street, Paris 75 005, France \\ ${ }^{2}$ Unifert Group S.A., 54 Louise Avenue, Immeuble Stéphanie, Bruxelles 1050, Belgium \\ Correspondence: Gérard Lucotte, Institute of Molecular Anthropology, 44 Monge Street, Paris 75 005, France. \\ E-mail: lucotte@hotmail.com
}

\author{
Received: September 5, 2014 Accepted: September 19, $2014 \quad$ Online Published: December 19, 2014 \\ doi:10.5539/jmbr.v5n1p1 URL: http://dx.doi.org/10.5539/jmbr.v5n1p1
}

\begin{abstract}
This paper describes the findings of the complete reconstruction of the lineage Y chromosome haplotype of the French Emperor Napoléon I. In a previous study (Lucotte et al., 2013) we reconstructed, for more than one hundred Y-STRs (Y-short tandem repeats), the Y-chromosome haplotype of Napoléon I based on data comparing STR allelic values obtained from the DNA of two of his living descendants: Charles Napoléon (C.N.) and Alexandre Colonna Walewski (A.C.W.); in the present study we compare STR allelic values of C.N. and A.C.W. to those of Mike Clovis (M.C.), a living fifth generation descendant of Lucien (one of Napoléon's brothers). When compared between M.C., C.N. and A.C.W., STR allelic values are identical for a total of 93 STRs; that permits us to propose those values, for which the three living descendants are identical, as expected allelic values of Napoléon I's Y-chromosome haplotype. For seven STRs, allele values are variable between M.C., C.N. and A.C.W.; we propose for three of them (DYS442, DYS454 and DYS712) expected allelic values, based on data concerning the allele distributions of these STRs in the population.
\end{abstract}

Keywords: Napoléon the First, lineage reconstruction, Y-chromosome haplotype

\section{Introduction}

The French Emperor Napoléon the First (1769-1821), was the son of Charles Bonaparte (1746-1785) and Letizia Ramolino (1750-1836). He had four brothers: Joseph (1768-1844), Lucien (1775-1840), Louis (1778-1846) and Jérôme (1784-1860).

In a first study (Lucotte et al., 2011) we determined the Y-chromosome non-recombinant part (NRY) haplogroup of Napoléon, based on genomic DNA extracted from two islands of follicular sheats associated with his beard hairs conserved in the Vivant-Denon reliquary (Lucotte, 2010). This haplogroup, established by the study of 10 NRY-SNPs (single nucleotide polymorphisms), is E1b1b1c1*; an "oriental" haplogroup of origin, as shown by the frequency map of M34 in contemporary European populations (Lucotte and Diéterlen, 2014), the antepenultimate SNP of the E1b1b1c1* differentiation.

In this same first study (Lucotte et al., 2011) we studied the buccal smear DNA of Charles Napoléon (C.N.), the living fourth generation of male descent from Jérôme, for the first 37 NRY-STRs (short tandem repeats) of the Family Tree DNA (FT DNA) kit; that permits us to establish a first Y-STR profile of C.N. This profile is highly indicative of the E1b1b1 haplogroup, because of STR allelic values at the discriminant (from Athey, 2006) Y-markers DYS19 (allele 13) and at DYS464.a, .b,.c and .d (alleles 13, 14, 15 and 16 respectively); moreover allele values (of 13) at DYS19 and at YCaII.a and .b (19 and 22) are the same for Napoléon (N) and for C.N.

In a second study (Lucotte et al., 2013) we established a more complete (because based on the FTDNA-111STRs kit) Y-STR profile of C.N., and the 111-Y-STRs profile of Alexandre Colonna Walewski (A.C.W.), the fifth generation descendant of Alexandre Walewski (1810-1868) who was the son born of the union between Napoléon I and Countess Maria Walewska (1786-1817). Comparisons at the time between the two STRs profiles were realized for a total number of 130 STRs, six of them (DYS454; DYS481; DYS635 = Y-GATA-C4; DYS712; DYS724 = CDY.a and DYF397.2) having different allelic values between C.N. and A.C.W. At that time we only had three direct determinations available on real allele values of Napoléon (for DYS19 $=13$, and for the palindromic YCAII. $a=19$ and $. b=22$ ). 
We then proposed (Lucotte et al., 2013) a first reconstruction of the Y-chromosome haplotype of Napoléon, based on the expected STR allelic values obtained from the 124 identical STRs between C.N. and A.C.W.

We have obtained now (Lucotte \& Bouin Wilkinson, 2014) sixteen supplementary allelic direct determinations (on a lock of hair dandruff dating from 1811) for Napoléon I STRs, in order; DYS $19=13$; palindromic DYS385.a and b. $=16$; DYS389. $\mathrm{i}=14$, .ii $=31$; DYS390 = 24; DYS391 = 10; DYS392 = 11; DYS393 = 14; DYS438 = 10; DYS439 $=$ Y-GATA-A $4=12$; DYS448 $=20$; DYS $456=15$; DYS458 $=16$; Y-GATA-C $4=23$ and Y-GATA-H 4 $=11$. These results confirm our previous ones for allele 13 at DYS19; moreover all these other direct determinations (except for Y-GATA-C4) are in accordance with our previous direct predictions (Lucotte et al., 2013) concerning the expected values for the corresponding STRs.

Mike Clovis (M.C.) is the fifth generation descendant (Figure 1) of Lucien; to visualize the generations of the two male descent from the Walewski and the Jérôme lines, see the first figure of the Lucotte et al., 2013 article. In order to realize a triangular comparison between three living males related to Napoléon I (a direct descendant: A.C.W.; an indirect descendant from his brother Jérôme: C.N.; and M.C., an indirect descendant from his brother Lucien), we study now in the present article the Y-STR profile of M.C. by means of the FT-DNA - 111 STRs kit; and we compare this STR profile to those of C.N. and A.C.W.

\section{Methods}

Mike Clovis (M.C.) is the propositus (Figure 1) for this study. Buccal swab samples for this DNA donor were collected with informed consent. DNA extraction and STRs typing ("upgrade" for 111 genetic markers) were done according to FTDNA recommendations.

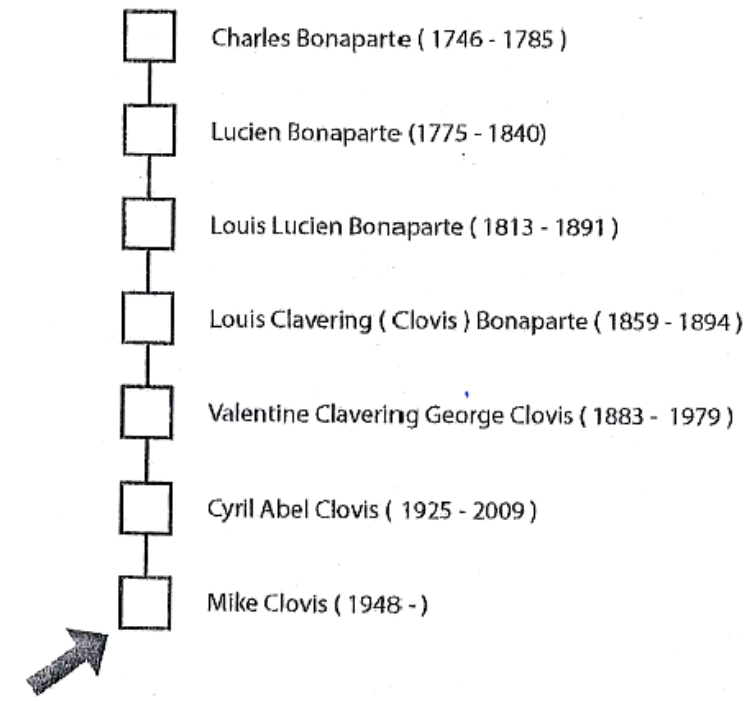

Figure 1. Chain of transmission (seven successive generations of paternal ancestry) from the ancestor Charles Bonaparte (Napoléon's father) to the propositus (arrow) Mike Clovis

\section{Results}

\subsection{Comparisons of STR Allelic Values Between M.C. and C.N. - A.C.W.}

Table 1 compares, for a total number of 106 STRs, allelic values obtained for M.C. to those of Charles Napoléon (C.N.) and Alexandre Colonna Walewsky (A.C.W.).

Seven STRs show different alleles between these three individuals, in order: DYS442 with an allele value $=11$ for M.C. compared to 12 for both C.N. and A.C.W.; DYS447 with an allele value $=22$ for M.C. compared to 21 for both C.N. and A.C.W.; for DYS454 the allele value $=11$ for M.C. is identical to that of A.C.W., C.N. having an allele value $=7$; for DYS481 the allele value $=27$ for M.C. is identical to that of C.N., A.C.W. having an allele value $=28$; for Y-GATA-C4 the allele value $=22$ for M.C. is identical to that of C.N., A.C.W. having an allele value $=21$; for DYS712 the allele value $=23$ for M.C. is identical to that of C.N., A.C.W. having an allele value $=$ 25; and for the palindromic CDY.a the allele value of M.C. $=34$ is identical to that of A.C.W., C.N. having an allele value $=35$. 
Table 1. Allelic values at 106 Y-STRs (numbers refer to the Y-markers of the FTDNA 111 "upgrade" for Mike Clovis (M.C.), Charles Napoléon (C.N.) and Alexandre Colonna Walewski (A.C.W.) NRY-DNAs. Asterisks indicate the seven differential markers (in italics) between M.C., and C.N. and A.C.W.

\begin{tabular}{|c|c|c|c|c|c|c|c|}
\hline \multirow{2}{*}{ Numbers } & \multirow{2}{*}{ Y-STRs } & \multicolumn{6}{|c|}{ Allelic values } \\
\hline & & Napoléon I & M.C. & C.N. & A.C.W. & Napoléon I & expected \\
\hline 3 & DYS19 = DYS394 & 13 & 13 & 13 & 13 & 13 & (direct determination) \\
\hline 5 & DYS385.a (palindromic) & 16 & 16 & 16 & 16 & 16 & (direct determination) \\
\hline 6 &.$b$ & 16 & 16 & 16 & 16 & 16 & (direct determination) \\
\hline 8 & DYS388 & & 12 & 12 & 12 & 12 & \\
\hline 10 & DYS389.i & 14 & 14 & 14 & 14 & 14 & (direct determination) \\
\hline 12 &. $\mathrm{ii}$ & 31 & 31 & 31 & 31 & 31 & (direct determination) \\
\hline 2 & DYS390 = DYS708 & 24 & 24 & 24 & 24 & 24 & (direct determination) \\
\hline 4 & DYS391 & 10 & 10 & 10 & 10 & 10 & (direct determination) \\
\hline 11 & $\begin{array}{l}\text { DYS392 } \\
\text { (located in the untranslated region } \\
\text { of the transcription unit TTTY10) }\end{array}$ & 11 & 11 & 11 & 11 & 11 & \\
\hline 1 & DYS393= DYS395 & 14 & 14 & 14 & 14 & 14 & (direct determination) \\
\hline 49 & DYS413.a (palindromic) & & 22 & 22 & 22 & 22 & \\
\hline 50 &.$b$ & & 22 & 22 & 22 & 22 & \\
\hline 48 & DYS425 (one copy of DYF371) & & 0 & 0 & 0 & 0 & \\
\hline 7 & DYS426 = DYS483 & & 11 & 11 & 11 & 11 & \\
\hline 105 & DYS434 & & 9 & 9 & 9 & 9 & \\
\hline 53 & DYS436 & & 12 & 12 & 12 & 12 & \\
\hline 19 & DYS437= DYS 457 & & 14 & 14 & 14 & 14 & \\
\hline 37 & $\begin{array}{l}\text { DYS438 } \\
\text { (located in the untranslated region } \\
\text { of the USP9 Y gene) }\end{array}$ & 10 & 10 & 10 & 10 & 10 & (direct determination) \\
\hline 9 & DYS439 = Y-GATA-A4 & & 12 & 12 & 12 & 12 & (direct determination) \\
\hline 89 & DYS441 & & 14 & 14 & 14 & 14 & \\
\hline 36 & DYS442* & & 11 & 12 & 12 & 12 & \\
\hline 57 & DYS444= DYS542 & & 11 & 11 & 11 & 11 & \\
\hline 86 & DYS445 & & 11 & 11 & 11 & 11 & \\
\hline 60 & DYS446 & & 12 & 12 & 12 & 12 & \\
\hline 18 & DYS $447 *$ & & 22 & 21 & 21 & $21 ?$ & \\
\hline 20 & DYS448 (located in the P3 loop) & 20 & 20 & 20 & 20 & 20 & (direct determination) \\
\hline 21 & DYS449 & & 28 & 28 & 28 & 28 & \\
\hline 56 & DYS450 & & 7 & 7 & 7 & 7 & \\
\hline 85 & DYS452 & & 30 & 30 & 30 & 30 & \\
\hline 17 & DYS454*= DYS639 & & 11 & 7 & 11 & 11 & \\
\hline 16 & $\begin{array}{l}\text { DYS455 } \\
\text { (located in the intron } 2 \text { of the TBL1 Y gene) }\end{array}$ & & 11 & 11 & 11 & 11 & \\
\hline 30 & DYS456 & 15 & 15 & 15 & 15 & 15 & (direct determination) \\
\hline 13 & DYS458 & 16 & 16 & 16 & 16 & 16 & (direct determination) \\
\hline
\end{tabular}




\begin{tabular}{|c|c|c|c|c|c|}
\hline 14 & DYS459.a (palindromic) & 9 & 9 & 9 & 9 \\
\hline 15 &.$b$ & 9 & 9 & 9 & 9 \\
\hline 26 & DYS460= Y-GATA-A7.1 & 10 & 10 & 10 & 10 \\
\hline 106 & DYS461 = Y-GATA-A7.2 & 11 & 11 & 11 & 11 \\
\hline 84 & DYS462 & 12 & 12 & 12 & 12 \\
\hline 88 & DYS463 & 18 & 18 & 18 & 18 \\
\hline 22 & DYS464.a (palindromic) & 14 & 14 & 14 & 14 \\
\hline 23 &.$b$ & 15 & 15 & 15 & 15 \\
\hline 24 &.$c$ & 16 & 16 & 16 & 16 \\
\hline 25 &.$d$ & 17 & 17 & 17 & 17 \\
\hline 45 & DYS472 & 8 & 8 & 8 & 8 \\
\hline 58 & DYS481* & 27 & 27 & 28 & 28 or $27 ?$ \\
\hline 69 & DYS485 & 15 & 15 & 15 & 15 \\
\hline 63 & DYS487= DYS698 & 14 & 14 & 14 & 14 \\
\hline 54 & DYS490 & 12 & 12 & 12 & 12 \\
\hline 66 & DYS492= DYS604 & 10 & 10 & 10 & 10 \\
\hline 80 & DYS494 & 9 & 9 & 9 & 9 \\
\hline 71 & DYS495 & 15 & 15 & 15 & 15 \\
\hline 103 & DYS497 & 14 & 14 & 14 & 14 \\
\hline 96 & DYS504= DYS660 & 16 & 16 & 16 & 16 \\
\hline 75 & DYS505 & 13 & 13 & 13 & 13 \\
\hline 104 & DYS510 & 17 & 17 & 17 & 17 \\
\hline 47 & DYS511 & 10 & 10 & 10 & 10 \\
\hline 97 & DYS513= DYS605 & 12 & 12 & 12 & 12 \\
\hline 59 & DYS520= DYS654 & 18 & 18 & 18 & 18 \\
\hline 79 & DYS522 & 12 & 12 & 12 & 12 \\
\hline 38 & DYS531= DYS600 & 10 & 10 & 10 & 10 \\
\hline 94 & DYS532 & 11 & 11 & 11 & 11 \\
\hline 81 & DYS533 & 11 & 11 & 11 & 11 \\
\hline 55 & DYS534 & 15 & 15 & 15 & 15 \\
\hline 43 & DYS537 & 12 & 12 & 12 & 12 \\
\hline 72 & DYS540 & 11 & 11 & 11 & 11 \\
\hline 77 & DYS549 & 12 & 12 & 12 & 12 \\
\hline 76 & DYS556 & 12 & 12 & 12 & 12 \\
\hline 51 & DYS557 & 21 & 21 & 21 & 21 \\
\hline 98 & DYS561 & 15 & 15 & 15 & 15 \\
\hline 67 & DYS565 & 11 & 11 & 11 & 11 \\
\hline 62 & DYS568 & 12 & 12 & 12 & 12 \\
\hline 33 & $\begin{array}{l}\text { DYS } 570 \\
\text { (located in the untranslated region of } \\
\text { the TBL1 Y gene) }\end{array}$ & 19 & 19 & 19 & 19 \\
\hline 64 & DYS572 & 11 & 11 & 11 & 11 \\
\hline
\end{tabular}




\begin{tabular}{|c|c|c|c|c|c|c|c|}
\hline 83 & DYS575 & & 8 & 8 & 8 & 8 & \\
\hline 32 & DYS576 & & 18 & 18 & 18 & 18 & \\
\hline 39 & DYS578 & & 8 & 8 & 8 & 8 & \\
\hline 101 & DYS587 & & 22 & 22 & 22 & 22 & \\
\hline 78 & DYS589 & & 11 & 11 & 11 & 11 & \\
\hline 42 & DYS589 & & 7 & 7 & 7 & 7 & \\
\hline 92 & DYS593 & & 16 & 16 & 16 & 16 & \\
\hline 52 & DYS594 & & 11 & 11 & 11 & 11 & \\
\hline 31 & DYS607 & & 12 & 12 & 12 & 12 & \\
\hline 61 & DYS617 & & 13 & 13 & 13 & 13 & \\
\hline 70 & DYS632 & & 8 & 8 & 8 & 8 & \\
\hline 100 & DYS635 $5^{*}=$ Y-GATA-C4 & 23 & 22 & 22 & 21 & 23 & (direct determination) \\
\hline 82 & DYS636 & & 11 & 11 & 11 & 11 & \\
\hline 65 & DYS640= DYS606 & & 13 & 13 & 13 & 13 & \\
\hline 44 & DYS641 & & 11 & 11 & 11 & 11 & \\
\hline 102 & DYS643 & & 12 & 12 & 12 & 12 & \\
\hline 93 & DYS650 & & 18 & 18 & 18 & 18 & \\
\hline 68 & DYS710 & & 31 & 31 & 31 & 31 & \\
\hline 91 & DYS712* & & 23 & 23 & 25 & 23 & \\
\hline 73 & DYS714 & & 24 & 24 & 24 & 24 & \\
\hline 95 & DYS715 & & 23 & 23 & 23 & 23 & \\
\hline 74 & DYS716 & & 28 & 28 & 28 & 28 & \\
\hline 34 & DYS724 = CDY.a $*$ (palindromic $)=$ gene & & 34 & 35 & 34 & $35 ?$ & \\
\hline 35 &.$b$ & & 36 & 36 & 36 & 36 & \\
\hline 99 & DYSS726 & & 15 & 15 & 15 & 15 & \\
\hline 87 & Y-GATA-A10 & & 12 & 12 & 12 & 12 & \\
\hline 27 & Y-GATA-H4 & 11 & 11 & 11 & 11 & 11 & (direct determination) \\
\hline 90 & Y-GGATT-1B07 & & 13 & 13 & 13 & 13 & \\
\hline 28 & YCAII.a (palindromic) & 19 & 19 & 19 & 19 & 19 & (direct determination) \\
\hline 29 &.$b$ & & 22 & 22 & 22 & 22 & (direct determination) \\
\hline 40 & DYF395S1.a (palindromic) & 22 & 15 & 15 & 15 & 15 & \\
\hline 41 &.$b$ & & 15 & 15 & 15 & 15 & \\
\hline 46 & DYF406S1 & & 10 & 10 & 10 & 10 & \\
\hline
\end{tabular}

Because you know exactly how many generations ago the ancestor lived (Figure 1), it is interesting to see how statistics / probabilities compare with reality. In this particular case: Mike $>$ Cyril $>$ Valentine-Louis Clavering $>$ Louis $>$ Lucien $>$ Charles Bonaparte (= Carlo Buonaparte), the probabilities based on the calculations of the time of the most recent common ancestor (the TMRCA) calculations (from Walsh, 2001) are incorrect: comparing the STRs showing only 6 mismatches, it only estimates the probability that Mike Clovis (328303) and Alexandre Colonna Walewski (218983) shared a common ancestor within the last 1 generation $=0.07 \%, 2$ generations $=$ $1.13 \%, 3$ generations $=4.93 \%, 4$ generations $=12.48 \%, 5$ generations $=23.38 \%, 6$ generations $=36.19 \%$, 7 generations $=49.27 \%, \ldots$; so, about 36 to $50 \%$ probability six generations back. 


\subsection{STRs with Identical Values}

A total number of 82 STRs have identical allelic values between M.C., C.N. and A.C.W.: in order, the 71 non-palindromic STRs DYS388 = 12; DYS425 = 0; DYS426 = 11; DYS434 = 9; DYS436 = 12; DYS437 = 14; DYS $441=14 ;$ DYS $444=11 ;$ DYS $445=11 ;$ DYS $446=12 ;$ DYS $449=28 ;$ DYS $450=7 ;$ DYS $452=30 ;$ DYS 455 $=11 ;$ DYS $460=10 ;$ DYS $461=11 ;$ DYS $462=12 ;$ DYS $463=18 ;$ DYS $472=8 ;$ DYS $485=15 ;$ DYS $487=14$; DYS490 $=12 ;$ DYS492 = 10;DYS494 = 9;DYS495 = 15;DYS497 = 14; DYS504 = 16; DYS505 = 13; DYS510 = 17;DYS511 = 10; DYS513 = 12; DYS520 = 18; DYS522 = 12; DYS531 = 10; DYS532 = 11; DYS533 = 11; DYS $534=15 ;$ DYS $537=12 ;$ DYS540 $=11 ;$ DYS $549=12 ;$ DYS556 $=12 ;$ DYS $557=21 ;$ DYS $561=15 ;$ DYS565 $=11 ;$ DYS568 $=12 ;$ DYS $570=19 ;$ DYS572 $=11 ;$ DYS $575=8 ;$ DYS576 $=18 ;$ DYS $578=8 ;$ DYS587 $=22$; DYS589 = 11; DYS590 = 7; DYS593 = 16; DYS594 = 11; DYS607 = 12; DYS617 = 13; DYS632 = 8; DYS636 = 11; DYS640 = 13; DYS641 = 11; DYS643 = 12; DYS650 = 18; DYS710 = 31; DYS714 = 24; DYS715 = 23; DYS716 = 28; DYS726 = 15; Y-GATA-A10 = 12; Y-GGAAT-1B07 $=13$ and DYF40651 $=10$.

Likewise for the 11 palindromic STRs: DYS413. $\mathrm{a}=22, \mathrm{~b}=22$; DYS459.a =9, $\mathrm{b}=9$; DYS464. $\mathrm{a}=14, \mathrm{~b}=15, \mathrm{c}=16$, $\mathrm{d}=17, \mathrm{CDY} . \mathrm{b}=36$ and DYF395S1. $\mathrm{a}=15, \mathrm{~b}=15$, which have identical values between M.C., C.N. and A.C.W.

Because of this identity, we can reasonably infer that the 93 allelic values of the above genetic markers correspond to those expected for Napoléon I (because they have remained unchanged for $5 / 6$ generations of remote ancestry).

\subsection{Differential STRS}

Table 2 lists and characterizes the seven STRs that differentiate between M.C., C.N., and A.C.W. Only one of them (CDY.a) is palindromic. The mutation rates, when known (Burgarella \& Navascués, 2011), of these differential alleles are in the $10^{-3}$ range (except for DYS447). These rates are impossible to evaluate for the palindromic STR CDY. a, and unknown for the moment for DYS712.

Table 2. Allele values for the seven differencial Y-STRs between Mike Clovis (M.C.), Charles Napoléon (C.N.) and Alexandre Colonna Walewski (A.C.W.). Expected allele values for $\mathbf{N}$ (Napoléon I) are established for the three Y-STRs DYS454 $=11$, DYS712 $=23$ and DYS442 $=12$

\begin{tabular}{|c|c|c|c|c|c|c|c|c|c|}
\hline \multirow{2}{*}{ Numbers } & \multirow{2}{*}{ Y-STRs } & \multirow{2}{*}{ Palindromic } & \multirow{2}{*}{$\begin{array}{l}\text { Mutation } \\
\text { rates }\end{array}$} & \multirow{2}{*}{$\begin{array}{c}\mathbf{N} \text { (direct } \\
\text { determination) }\end{array}$} & \multicolumn{3}{|c|}{ Allele values } & \multirow{2}{*}{$\begin{array}{c}\text { Racial } \\
\text { background }\end{array}$} & \multirow{2}{*}{$\begin{array}{c}\mathbf{N} \\
\text { (deduced / } \\
\text { expected values) }\end{array}$} \\
\hline & & & & & & & & & \\
\hline 1 & Y-GATA-C4 & & $2.832 \times 10-3$ & 23 & 22 & 22 & 21 & & \\
\hline 2 & DYS454 & & $2.182 \times 10^{-3}$ & & 11 & 7 & 11 & & 11 \\
\hline 3 & DYS712 & & $?$ & & 23 & 23 & 25 & & 23 \\
\hline 4 & DYS442 & & $1.926 \times 10^{-3}$ & & 11 & 12 & 12 & & 12 \\
\hline 5 & DYS447 & & $7.414 \times 10^{-4}$ & & 22 & 21 & 21 & $+?$ & $21 ?$ \\
\hline 6 & DYS481 & & $6.937 \times 10^{-3}$ & & 27 & 27 & 28 & + & $27-28 ?$ \\
\hline 7 & CDY.a & + & & & 34 & 35 & 34 & & $35 ?$ \\
\hline
\end{tabular}

We already know (Lucotte \& Bouin-Wilkinson, 2014) the real allele value $=23$ of Y-GATA-C4 for Napoléon I. Figure 2 shows the bimodal distribution of Y-GATA-C4 alleles in the population; Napoléon I (N) value corresponds to that of the second modal class. Allele values $(=22)$ of Charles Napoléon (C.N.) and Mike Clovis (M.C.) can be explained admitting one-step (minus 1) mutations, and that (=21) of Alexandre Colonna Walewsky (A.C.W.) admitting a two-step (minus 2) mutation. 


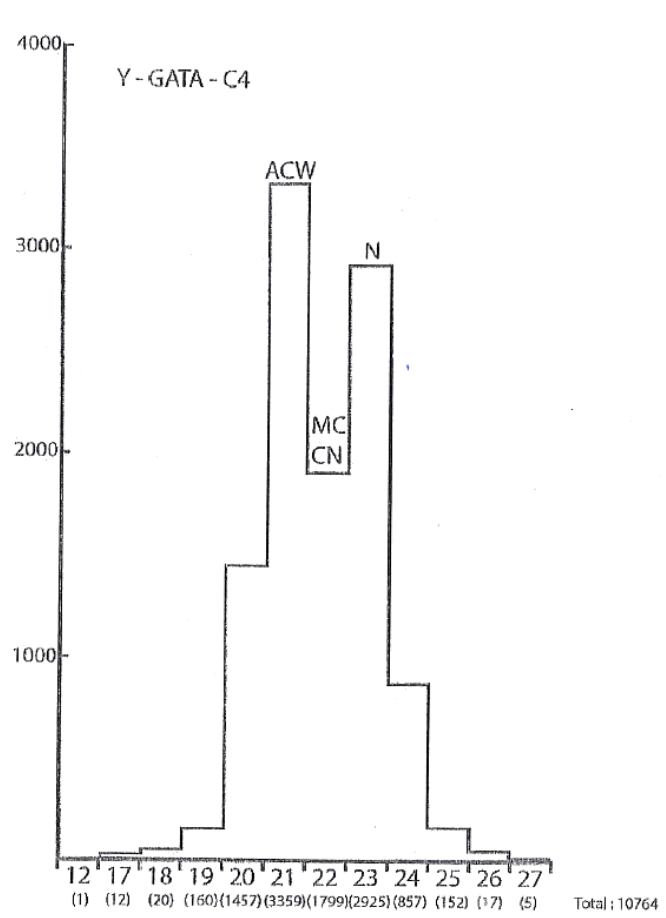

Figure 2. Y-GATA-C4 allelic distribution (www.genebase.com/in/dnaMarkerDetail.php?t=y\&d =DYS635), based on values from 10764 subjects

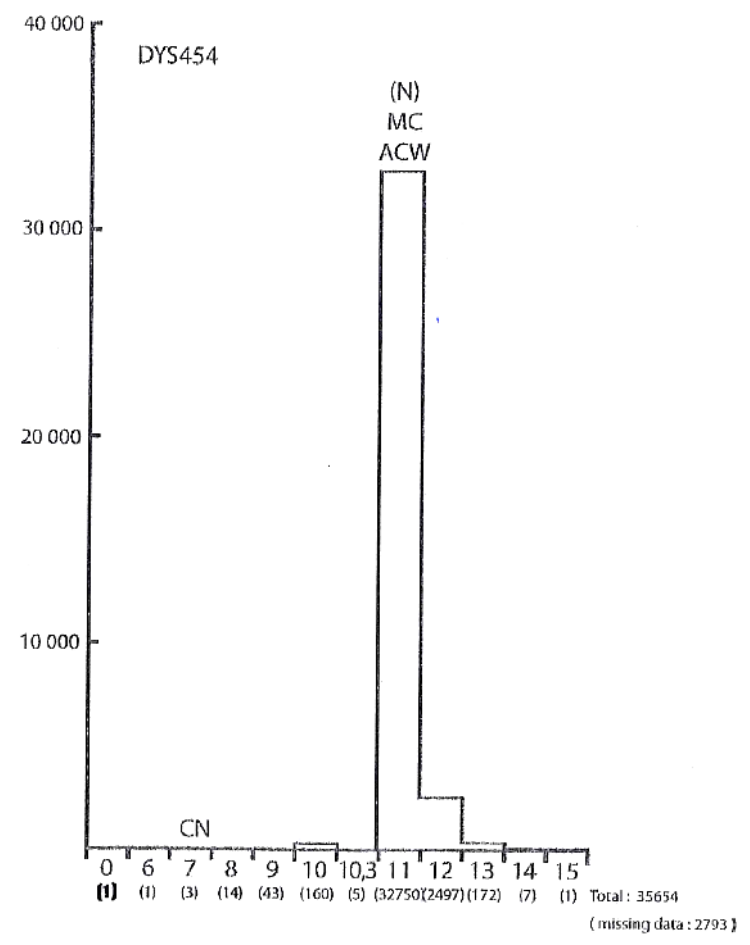

Figure 3. DYS454 allelic distribution (CEPH database), based on values from 35654 subjects

The distribution of DYS454 alleles in the population is shown in Figure 3. According to Redd et al. (2002) DYS454 is one of the most stable (with a pre-eminent modal class $=11$ ) of the marker set. Because both A.C.W. and M.C. alleles belong to this modal class, the most parsimonious interpretation is that allele 11 at this marker is the ancestral form - that of Napoléon I (N) - and that the allele value $=7$ for C.N. represents a derived one, which happened during one of the five generations separating C.N. from the common ancestor Carlo Buonaparte. It is probable that this variant 7 (characteristic of the Jérôme line) is due to a multistep deletion, a rare event which often results in a most stable allele (Lucotte et al., 2013).

Although based on a relatively low number of subjects studied, figure 4 shows a representative allele distribution for DYS712. The interest of this recently described marker is that it certainly represents one of the most variable STR of the panel (its modal class corresponds to allele 22). Alleles of C.N. and M.C. $=23$ and the A.C.W. allele $=$ 25 . The expected $\mathrm{N}$ value is probably 23 , because this class corresponds to the second one in importance; and the A.C.W. value $=25$ must be due to a two-step (plus 2 ) mutation.

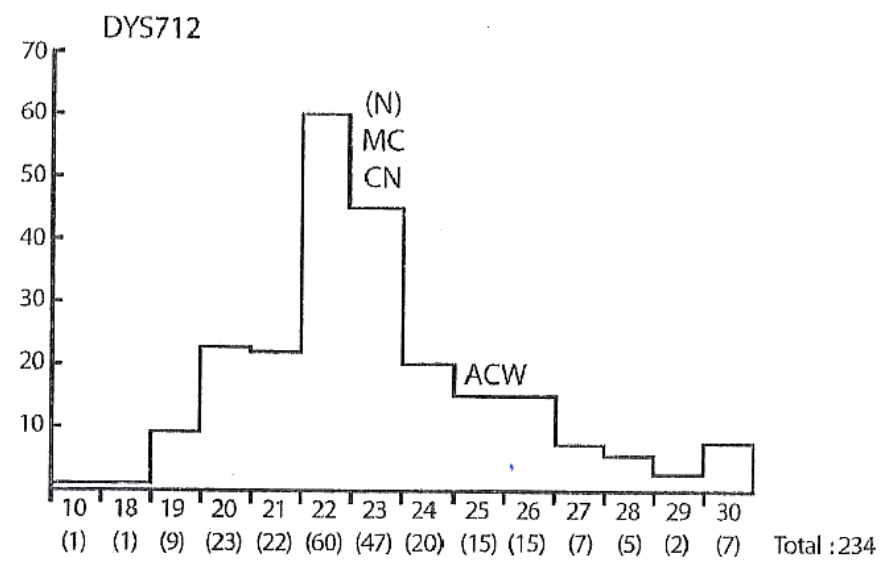

Figure 4. DYS712 allelic distribution (K. Norved, personal communication) of 234 American Caucasians 
Figure 5 shows the modal distributions of alleles for DYS442 and DYS447, based on a sample of 1000 European subjects (English: 56, Germans: 59, French Parisians: 191, French Basques: 97, Corsicans: 328, North Italians: 46, Central-Italians: 112, Sardinians: 111; from Diéterlen and Lucotte, 2005). For DYS442 the allele value $=12$ of C.N. and A.C.W. corresponds to the modal class; so it is probable that the expected $\mathrm{N}$ value is 12 . The value $=11$ for M.C. must correspond to a one-step (minus 1) mutation.

The pattern of variations is more complicated to interpret for DYS447, because none of the allele values is located at the modal $(=25)$ nor at the adjacents (26 and 24) classes: allele values for C.N. and A.C.W. $=21$, and 22 for M.C. We presume that the DYS447 distribution presents a small peak in frequencies (possibly due to racial background) at the left tail of the modal class. In this hypothesis, but it is highly speculative, the expected $\mathrm{N}$ value could be $=21$ (because of the two 21 allelic values of C.N. and A.C.W.).
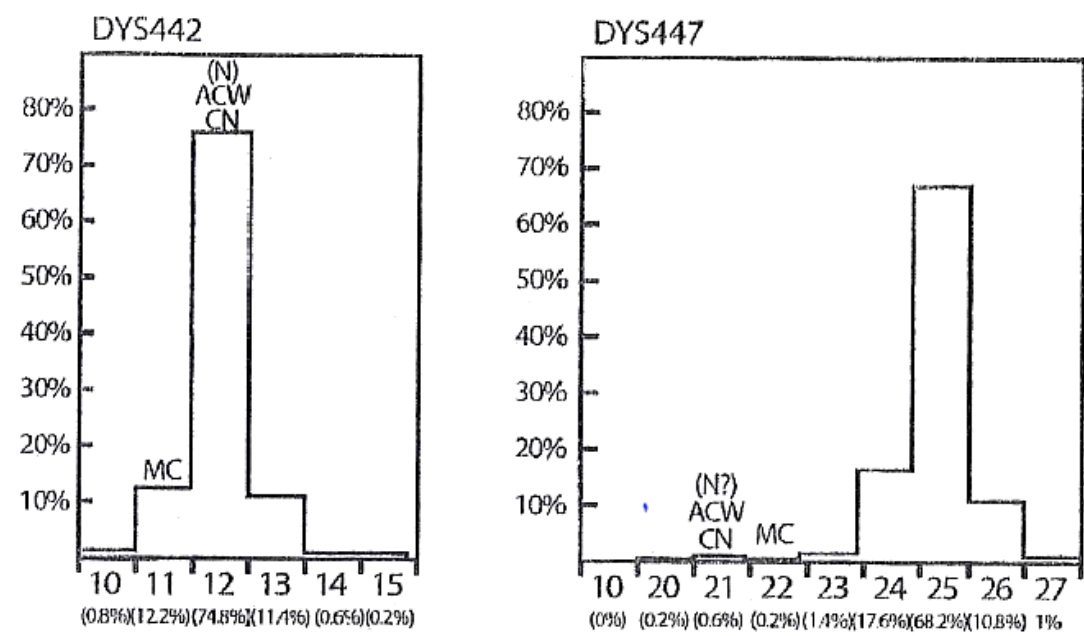

Figure 5. DYS442 and DYS447 allelic distributions, based on our sample of 1000 unrelated European Caucasians

The existence of this racial background is evident for DYS481 (English: 102, Indians: 83, Africa: 94; from D'Amato et al., 2010), where the three European, Asiatic and African distributions are superposed on the graph (Figure 6): the 27 (for C.N. and M.C.) and 28 (for A.C.W.) classes are relatively well represented at the right tail of the Asiatic distribution, but none (for 27) or few (for 28) for the European distribution; but in any case we cannot decide if the expected $\mathrm{N}$ value is 27 or 28 .

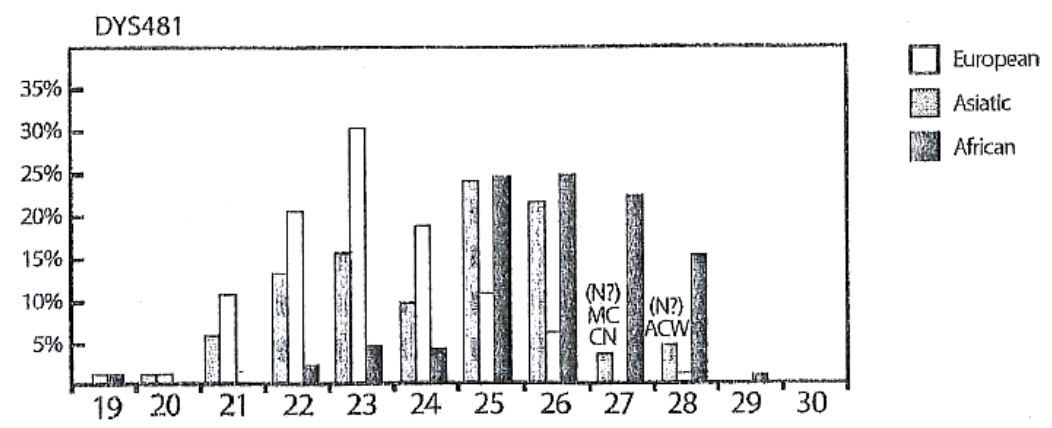

Figure 6. DYS481 allelic distribution (from d' Amato et al., based on samples of 102 European subjects (English), 83 Indians and 94 Xhosas

This sort of racial context intervening for some STR alleles determining the Y-haplotype is interesting to consider, because of the oriental origin (Lucotte \& Diéterlen, 2014) of the E1b1b1 haplogroup of Napoléon I, more precisely known now (Lucotte et al., 2013) as E1b1b1b2a1 L792 ${ }^{+}$haplogroup.

Figure 7 shows the modal distributions - based on our sample of 1000 European subjects - of allelic classes for the palindromic markers CDY.a and CDY.b. It is because of the identity of allele values $=36$ between C.N., A.C.W. 
and M.C. that we proposed that the expected N value for CDY.b is 36. (though it corresponds to the fourth frequency class in importance, located at the left tail of the modal class).
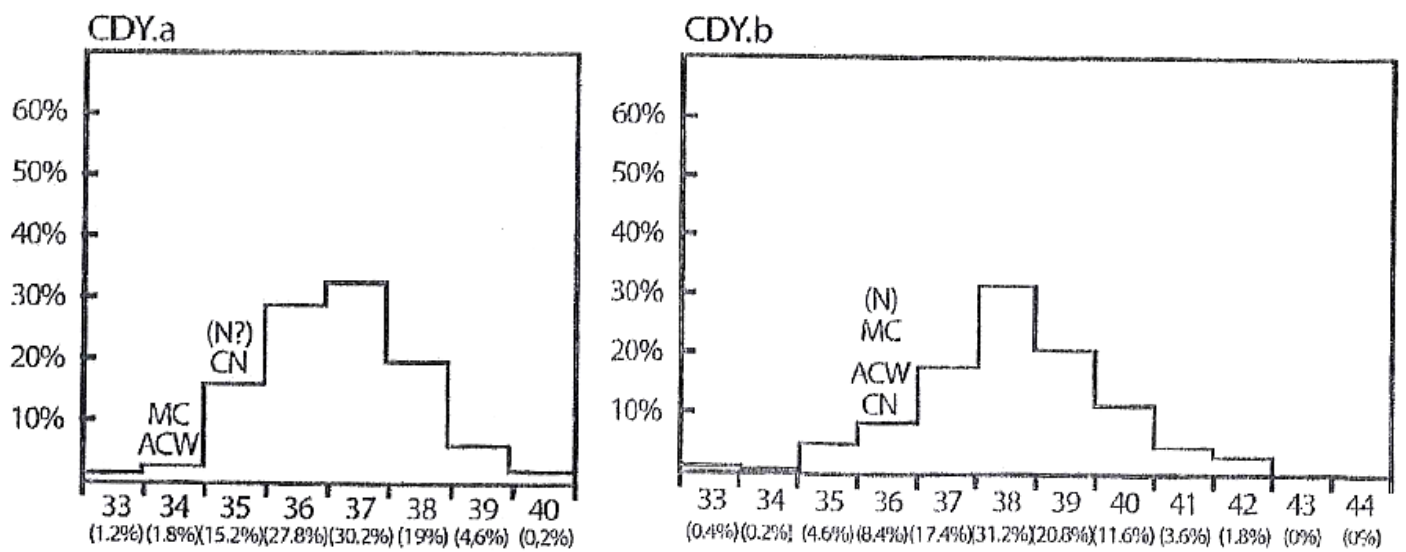

Figure 7. CDY.a and .b allelic distributions, based on the sample of 1000 unrelated European Caucasians

Predictions about the variation of palindromic Y-STRs, even in the more simple situation of a two-copy marker like CDY, is a very hazardous matter (Lucotte et al., 2013) because we do not know exactly the precise mechanisms involved. For CDY.a the C.N. allelic value $=35$, and the A.C.W. and M.C. values $=34$. We retain here the possibility, but it is also highly speculative, that the expected $\mathrm{N}$ value could be $=37$ (because, as for CDY.b, it corresponds to the third frequence class, located at the left tail of the modal one). Certainly the 35 alleles for A.C.W. and M.C. cannot be explained by such a simple mechanism as that of one-step (minus 1) mutation.

\section{Discussion}

In the goal to establish the Y-chromosome haplotype of Napoléon the First we determined initially, in his genomic DNA extracted from two islands of follicular sheats associated with his beard hairs conserved in the Vivant-Denon reliquary (Lucotte et al., 2011), allelic values for the three Y-STRs DYS19 and for two palindromic STRs YcaII.a and .b. Subsequently (Lucotte and Bouin-Wilkinson, 2014), based on genomic DNA of his hair dandruff dating from 1811, we determined allelic values for 16 STRs: DYS19 (for which we confirmed the first allelic value previously obtained), the palindromic STRs DYS385.a and .b, DYS389.i and ii, DYS390, DYS391, DYS392, DYS393, DYS438, the variable STR-Y-GATA-A4, DYS448, DYS456, DYS458, Y-GATA-C4 and Y-GATA-H4. The corresponding allele values for these 18 STRs correspond to the real allelic values of the Napoléon I Y-haplotype.

Because of the identity of allelic values of STRs between Charles Napoléon (the living fourth generation of male descent from Jérôme (Napoléon I's youngest brother) and Alexandre Colonna Walewski (a direct living sixth generation descendant from Napoléon I), we proposed (Lucotte et al., 2013) expected allelic values of Napoléon I for a total number of 109 STRs (33 of them being palindromics). For some of the six variables (between Charles and Alexandre) STRs: DYS454, DYS481, Y-GATA-C4, DYS712, CDY.a (palindromic) and DYF397.2 (palindromic), we proposed as expected allelic values for Napoléon I the most probable allelic forms according to STR distributions; the allele value of DYS454 $=7$ for Charles Napoléon appeared then as a highly discordant one.

Mike Clovis is a living, previously unknown, fifth descendant of Lucien (another brother of Napoléon I). The objective of the present study is to compare, for a total number of 106 STRs, allelic values between him, Charles Napoléon and Alexandre Colonna Walewski. Identity of allelic values between the three was confirmed for 82 non-palindromic STRs and for 11 palindromic STRs; that confirms, in a triangular form, that these 93 STR allelic values are definitely those previously proposed as expected allele values of the Napoléon I Y-haplotype.

These comparisons between Mike Clovis, Charles Napoléon and Alexandre Colonna Walewsky permit us to clarify some of the questions asked by the variable values between them: for DYS454, the allele value $=11$ for Mike Clovis is the expected allelic value of Napoléon I, as previously proposed. For DYS712, the allele value $=23$ for Mike Clovis corresponds also to the expected allelic value of Napoléon I already proposed; however in this case it is not the modal class of distribution of DYS71 values that is concerned, but the nearest one of the right edge of this distribution. 
Compared to Charles Napoléon and Alexandre Colonna Walewski, Mike Clovis had different allele values for DYS442 $=11$ and DYS $447=22$. For DYS442, as proposed previously, allele value $=12$ is probably the expected allelic value of Napoléon I because it corresponds to the modal class of the distribution; and allele value $=11$ for Mike Clovis results from a single mutational event (one-step, minus 1).

It is impossible to predict some expected allelic value of Napoléon I for DYS447, because the three obtained allele values (that of Mike Clovis $=22$ could be the result of a one-step plus 1 mutational event) are all located at the left tail of the distribution. It is impossible also to predict some expected allelic value of Napoléon I for DYS481, even when interpreted in the context of the oriental origin of the E1b1b1c1 haplogroup (Lucotte and Diéterlen, 2014), because all the three obtained allele values are now located at the right tail of the distribution.

We ignore, for the moment, what is the Y-chromosome haplotype of Carlo Buonaparte; but it seems highly probable, because of the similarities between the Y-STR values presently obtained, that he was the biological father of Lucien, Napoléon and Jérôme (all these three having the same Y-haplogroup). As a by-product of such studies, we established that the allele value $=7$ for DYS545 is highly characteristic of the Jérôme line; possibly, as shown here, the allele value $=11$ for DYS442 could be characteristic of the Lucien line. It remains a possibility that allele values of 25 for DYS712 and of 28 for DYS481 could be characteristics of the direct Napoléon I line, at least for the Walewski descent.

\section{References}

Athey, W. T. (2006). Haplogroup prediction from Y-STR values using a Bayesian allele frequency approach. $J$. Genet. Geneal., 2, 34-39.

Burgarella, C., \& Navascués, M. (2011). Mutation rate estimates for 110 Y-chromosome STRs combining population and father-son pair data. Eur. J. Hum. Genet., 19, 70-75. http://dx.doi.org/10.1038/ejhg.2010.154

D’Amato, M. E., Ehrenreich, L., Cloete, K.,Benjeddou, M., \& Davison, S. (2010). Characterization of the highly discriminatory loci DYS449, DYS481, DYS518, DYS612, DYS626, DYS644 and DYS710. Forens. Sci. Int. Genet., 4, 104-110. http://dx.doi.org/10.1016/j.fsigen.2009.06.011

Diéterlen, F., \& Lucotte, G. (2005). Haplotype XV of the Y-chromosome is the main haplotype in West-Europe. Biomed. Pharmacother, 59, 269-272. http://dx.doi.org/10.1016/j.biopha.2004.08.023

Lucotte G., \& Bouin-Wilkinson, A. (2014). An autosomal STR profile of Napoléon the First. Op. J. Genet., 4, 292-299. http://dx.doi.org/10.4236/ojgen.2014.44027

Lucotte, G. (2010). A rare variant of mtDNA HSV1 sequence in the hairs of Napoléon's family. Invest. Genet., 1, 1-4. http://dx.doi.org/10.1186/2041-2223-1-7

Lucotte, G., \& Diéterlen, F. (2014). Frequencies of M34, the ultimate genetic marker of the terminal differenciation of Napoléon the First's Y-chromosome haplogroup E1b1b1c1 in Europe, Northern Africa and the Near East. Int. J. Anthropol., 29(1-2), 27-41

Lucotte, G., Macé, J., \& Hrechdakian, P. (2013). Reconstruction of the lineage Y chromosome haplotype of Napoléon the First. Int. J. Sciences., 9, 127-139.

Lucotte, G., Thomasset, T. \& Hrechdakian, P. (2011). Haplogroup of the Y chromosome of Napoléon the First. J. Mol. Biol. Res., 1, 12-19. http://dx.doi.org/10.5539/jmbr.v1n1p12

Redd, A. J., Agellon, Al B., Kearney, V. A., Contreras, V. A., Karafet, T., Park, H., ... Hammer, M. F. (2002). Forensic value of 14 novel STRs on the human Y chromosome. Forens. Sci. Int., 130, 97-111. http://dx.doi.org/10.1016/S0379-0738(02)00347-X

Walsh, B. (2001). Estimating the time of the most recent ancestor for the Y chromosome or mitochondrial DNA for a pair of individuals. Genetics, 158, 897-912.

\section{Copyrights}

Copyright for this article is retained by the author(s), with first publication rights granted to the journal.

This is an open-access article distributed under the terms and conditions of the Creative Commons Attribution license (http://creativecommons.org/licenses/by/3.0/). 